\title{
Factors that influence the implementation of e-health: a systematic review of systematic reviews (an update)
}

\author{
Jamie Ross ${ }^{*}(\mathbb{D}$, Fiona Stevenson, Rosa Lau and Elizabeth Murray
}

\begin{abstract}
Background: There is a significant potential for e-health to deliver cost-effective, quality health care, and spending on e-health systems by governments and healthcare systems is increasing worldwide. However, there remains a tension between the use of e-health in this way and implementation. Furthermore, the large body of reviews in the e-health implementation field, often based on one particular technology, setting or health condition make it difficult to access a comprehensive and comprehensible summary of available evidence to help plan and undertake implementation. This review provides an update and re-analysis of a systematic review of the e-health implementation literature culminating in a set of accessible and usable recommendations for anyone involved or interested in the implementation of e-health.

Methods: MEDLINE, EMBASE, CINAHL, PsycINFO and The Cochrane Library were searched for studies published between 2009 and 2014. Studies were included if they were systematic reviews of the implementation of e-health. Data from included studies were synthesised using the principles of meta-ethnography, and categorisation of the data was informed by the Consolidated Framework for Implementation Research (CFIR).

Results: Forty-four reviews mainly from North America and Europe were included. A range of e-health technologies including electronic medical records and clinical decision support systems were represented. Healthcare settings included primary care, secondary care and home care. Factors important for implementation were identified at the levels of the following: the individual e-health technology, the outer setting, the inner setting and the individual health professionals as well as the process of implementation.

Conclusion: This systematic review of reviews provides a synthesis of the literature that both acknowledges the multi-level complexity of e-health implementation and provides an accessible and useful guide for those planning implementation. New interpretations of a large amount of data across e-health systems and healthcare settings have been generated and synthesised into a set of useable recommendations for practice. This review provides a further empirical test of the CFIR and identifies areas where additional research is necessary.
\end{abstract}

Trial registration: PROSPERO, CRD42015017661

Keywords: Implementation, e-Health, Systematic review, Update, Synthesis

\footnotetext{
*Correspondence: Jamie.Ross@ucl.ac.uk

e-Health Unit, Research Department of Primary Care and Population Health,

University College London, Upper 3rd Floor, Royal Free Campus, Rowland Hill

Street, London NW3 2PF, UK
} 


\section{Background}

Technology is used extensively to provide and deliver health care worldwide [1, 2]. e-Health (the application of information, computer or communication technology to some aspects of health or health care) is viewed as essential for solving problems facing healthcare systems of increasing demand, due to an ageing population and improved treatments, and limited resources [3]. However, although there is widespread agreement about the importance and potential benefits of e-health, realisation of these benefits has often been slower than anticipated, often because of difficulties with implementation [4]. For example, in the UK, the National Health Service (NHS) Five Year Forward View [5] states the need to make better use of available health technologies and acknowledges that the NHS has previously failed to make best use of these because of difficulties in understanding how best to adopt and implement them. High-profile implementation failures continue to be reported, such as the failure of implementation of an e-health system in a major UK teaching hospital, leading to reduced performance, demoralised staff, costs of $£ 200$ million and the trust being put into special measures [6]. This highlights the strong need for those undertaking the implementation of e-health to understand factors that influence implementation and be well equipped to devise strategies and interventions to improve the widespread effective use of e-health and address blockages to implementation.

One problem with the current e-health implementation literature is that it is fragmented across multiple subspecialty areas [7]. With a plethora of reviews on the implementation of different e-health technologies available, it may be difficult for clinicians, managers or policymakers to locate and apply an appropriate body of evidence for their specific circumstances.

The aim of this systematic review of reviews was to provide a synthesis of the implementation of e-heath literature that both acknowledges the multi-level complexity of implementation and also provides a framework for thinking about implementation in a way that is accessible and useful for those planning implementation such as health service managers, healthcare professionals and researchers. Specific objectives were to (i) identify published reviews pertaining to implementation of e-health systems; (ii) summarise the data contained in these reviews; (iii) synthesise these data according to the Consolidated Framework for Implementation Research (CFIR) [8]; and (iv) provide recommendations for future implementations of e-health systems. The CFIR provides a systematic way of identifying the factors that are important for implementation, and its use also allows identification of areas where there is insufficient evidence and further research is required.

\section{Methods/design}

The protocol for this systematic review has been published [9] and registered with the Prospective Register of Systematic Reviews (registration number CRD42015017661).

A systematic review of reviews by Mair et al. [7] synthesised the literature on the implementation of e-health interventions in healthcare settings published up until 2009. As the use of e-health is rapidly growing and changing, and the nature of healthcare systems are continually shifting, an update of this review was deemed timely. A systematic review of reviews was deemed to be the most appropriate method, as opposed to a systematic review of the primary literature, as the huge number of primary studies in the area would make synthesis potentially unworkable and very time consuming. A systematic review of reviews provides a summary of evidence from a variety of different levels, including the combination of different interventions, different populations and different settings [10] in a coherent and economical way [7]. Separate reviews are brought together, compared and contrasted, which allows for new insights to be generated across the literature and synthesised into a simple overview of a large body of work.

This update largely replicated the methods for identifying and selecting studies described in the original review [7] but, as detailed, differs in the methods of data analysis. For reader clarity, henceforth, the following terms shall be used to describe the reviews referred to.

- Review-the current systematic review of review

- Original review-the systematic review of reviews conducted by Mair et al. [7]

- Studies/papers-the systematic reviews identified and synthesised in this review of reviews

\section{Reporting}

This systematic review is reported following the ENTREQ statement guidelines to enhance transparency in reporting qualitative evidence synthesis [11].

\section{Inclusion and exclusion criteria}

The eligibility criteria for study inclusion (replicated from the Mair review) were developed using the acronym PICOS (see Table 1).

\section{Search strategy for identification of studies}

Comprehensive electronic searches of MEDLINE, EMBASE, CINAHL, PsycINFO and The Cochrane Library were conducted.

The search strategy, which was replicated from the original review, was based on the following two concepts: e-health and implementation. The search strategy included a combination of Medical Subject Headings and free-text words. The MEDLINE (Ovid) search 
Table 1 Eligibility criteria for study inclusion

Population Healthcare settings (including but not limited to primary intermediate, secondary, home care).

All healthcare settings were considered.

Not limited by: clinical area, health concern; the type of patient receiving the e-health technology; the type of health professional delivering care or country.

Intervention e-Health technologies (including management systems, such as electronic health records that allow the acquisition, transmission and storage of patient data; computerised decision support systems including diagnostic support, alerts and reminder systems; communication systems such as telecommunication that act as an intermediary between users; and information resources such as the Internet)

Comparator This review was not limited to comparator studies.

Outcomes Qualitative data on factors that inhibit or promote implementation of e-health.

Study type Papers were included if they were as follows:

- Systematic reviews: where relevant literature had been identified by means of structured search of bibliographic and other databases, where transparent methodological criteria were used to exclude papers that did not meet an explicit methodological benchmark, and which presented rigorous conclusions about outcomes.

- Narrative reviews: where relevant literature had been purposively sampled from a field of research; where theoretical or topical criteria were used to include papers on the grounds of type, relevance and perceived significance; with the aim of summarising, discussing and critiquing conclusions

- Qualitative meta-syntheses or meta-ethnographies, where relevant literature was identified by means of a structured search of bibliographic and other databases, where transparent methods had been used to draw together theoretical products, with the aim of elaborating and extending theory.

And were excluded if they were as follows:

- Secondary analyses (including qualitative meta-syntheses or meta-ethnographies) of existing data-sets for the purposes of presenting cumulative outcomes from personal research programmes.

- Secondary analyses (including qualitative meta-syntheses or meta-ethnographies) of existing data-sets for the purposes of presenting integrative outcomes from different research programmes.

- Discussions of literature included in contributions to theory building or critique.

- Summaries of literature for the purposes of information or commentary.

- Editorial discussions that argue the case for a field of research or a course of action.

Where an abstract stated it was a review, but there was no supporting evidence in the main paper, such as details of databases searched or criteria for selection of papers (either on methodological or theoretical grounds), the paper was excluded.

strategy that was used to identify papers is presented in Additional file 1. There was no limitation of language. Citation searches were carried out in ISI Web of Science in September 2015 and results were limited, in line with the search strategy, to studies published up until 1 January 2014. Reference lists of all included studies were also screened for additional literature.

The original review [7] was based on 37 papers published between 1995 and 31 July 2009. The search strategy used in the original review was replicated to identify additional literature published from 1 August 2009 until 1 January 2014. The 37 papers identified by the original review were also screened for inclusion in the current review; hence, this review includes papers identified through systematic searches of the literature published between 1995 and 2014.

\section{Selection of studies}

Search results were imported into the EndNote reference management software, and duplicates were removed automatically and double checked manually. Titles and abstracts of all identified records were independently assessed by JR and RL. Full-text papers of references that were deemed potentially eligible were obtained and assessed for eligibility against the pre-specified selection criteria. Any discrepancies between reviewers were resolved through discussion. Reasons for exclusion at this stage were recorded and are detailed in the Preferred Reporting Items for Systematic Reviews and MetaAnalyses (PRISMA) diagram [12] (see Fig. 1).

\section{Study quality assessment}

Data on the methodological quality of the included reviews was extracted based on ENTREQ statement guidelines [11] and was used to describe the quality of the included reviews. Because the aim was to describe and synthesise a body of qualitative literature and not determine an effect size, studies were not excluded based on this assessment.

\section{Data extraction}

An excel spreadsheet was created for the purposes of data extraction which contained a row for each included review and columns to describe the studies and classify the extracted data related to the implementation of ehealth. Data were extracted from the included studies by $\mathrm{JR}$, and data extraction and coding was checked by EM.

\section{Data synthesis}

The original review had used a thematic approach to analysing and synthesising the data, together with an analysis based on normalization process theory, which focusses on the work of implementation. In view of the large amount of new data, and the subsequent development of the CFIR [10], which pays more detailed attention to aspects such as legislative or financial frameworks, we decided to update the analytic approach to use an approach which drew 


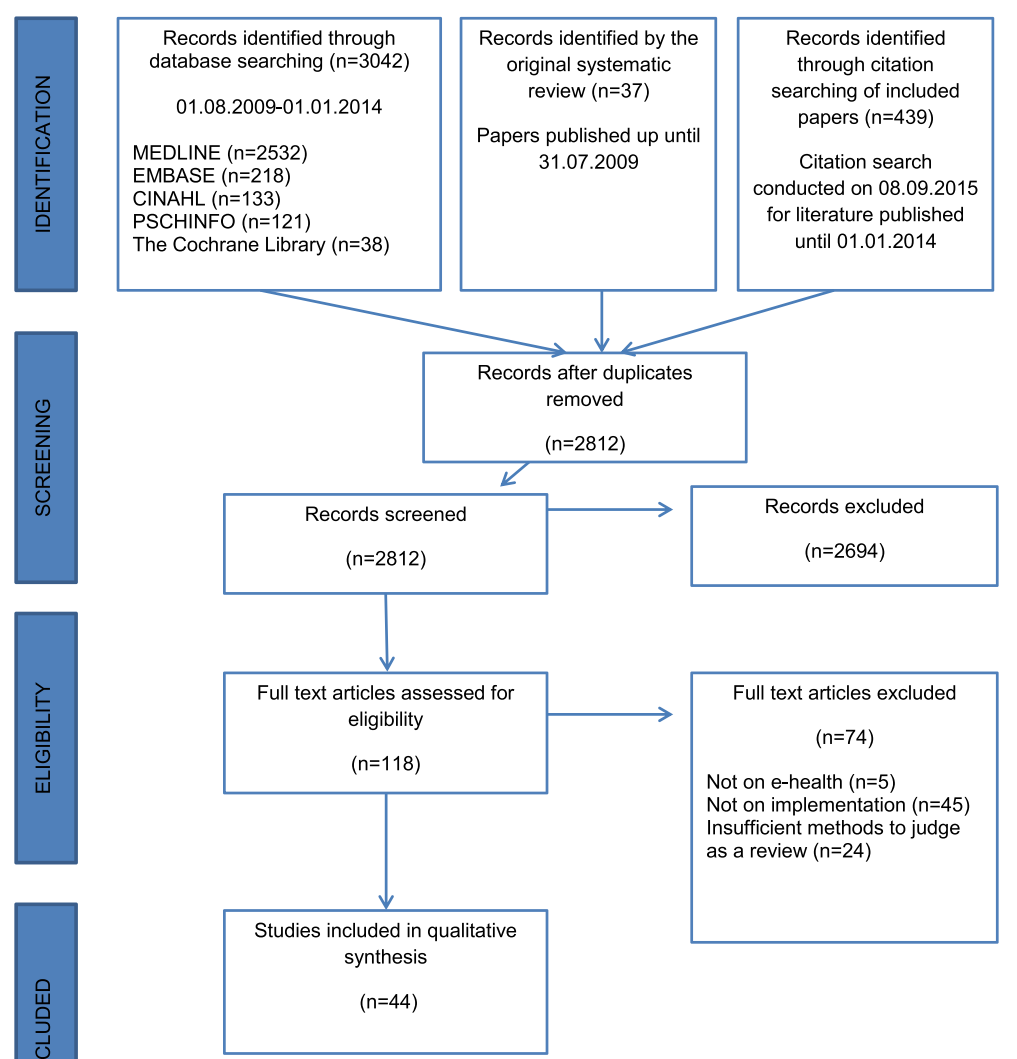

Fig. 1 PRISMA flow diagram of study selection

on the principles of meta-ethnography for data synthesis, with the CFIR as an organising framework. The use of a framework like the CFIR aids the transferability and comparability of findings from this review to other implementation studies and allows those undertaking implementation to access the parts of this review that are of most interest to them. The CFIR [8], consolidates implementation factors from a broad array of implementation theories and is composed of five major constructs made up of components that influence the implementation of innovations into practice (see Table 2).

Meta-ethnography, as described in depth by Noblit and Hare [13], focusses on interpretation to 'synthesise understanding, unlike other approaches to qualitative synthesis, such as thematic analysis, which seek to summarise data [14]. Noblit and Hare describe seven key steps: (i) getting started, (ii) deciding what is relevant to the initial interest, (iii) reading the studies, (iv) determining how the studies are related, (v) translating the studies into one another, (vi) synthesising translations, (vii) and expressing the synthesis. We draw on these steps to consider novel interpretations from combining data within the studies identified. Steps i-iii were incorporated into the steps described above. We provided more detail below in respect of subsequent steps.

\section{Determining how studies are related}

A data extraction form was developed to extract key information and concepts from the included studies and to ease comparison between them. Data were firstly extracted to describe the type of study including publication date, e-health domain, healthcare setting, inclusion and exclusion criteria and methods used. Secondly, the main themes from each review relating to factors that influence implementation of e-health were extracted from both results and discussion sections of the included papers. Data from discussions were included as they often contained further interpretations from the authors, which offered important insights and enhanced the richness of the findings. A summary table created from this matrix with key study details, and summaries of main findings are presented in Additional file 2.

\section{Translating the studies into one another}

Following inductive analysis of the results and discussion sections of the included papers, it became clear that data 
Table 2 Summary of findings of factors important for the implementation of e-health

\begin{tabular}{|c|c|c|c|c|c|c|c|c|}
\hline \multirow[t]{2}{*}{ CFIR construct } & \multirow[t]{2}{*}{ CFIR component } & \multirow[t]{2}{*}{ CFIR sub-component } & \multirow[t]{2}{*}{ Sources } & \multicolumn{5}{|c|}{ e-Health domain } \\
\hline & & & & MS & CS & $C D$ & IS & RS \\
\hline \multirow{8}{*}{$\begin{array}{l}\text { Innovation } \\
\text { characteristics }\end{array}$} & Innovation source & & {$[16,18]$} & $x$ & & & & \\
\hline & $\begin{array}{l}\text { Evidence strength and } \\
\text { quality }\end{array}$ & & {$[17,18,20,22,25,53,57]$} & $x$ & $x$ & & & $x$ \\
\hline & Relative advantage & & {$[17,25,31,34,38,43,49,51,57]$} & & $x$ & $x$ & $x$ & $x$ \\
\hline & Adaptability & & $\begin{array}{l}{[16,18,21,22,24,25,27,28,34,35,38,39,} \\
41,48-50,52,53,58]\end{array}$ & $x$ & $x$ & $x$ & $x$ & $x$ \\
\hline & Trialability & & {$[41,51]$} & $x$ & $x$ & & & \\
\hline & Complexity & & $\begin{array}{l}{[18,27,28,34,38,40,41,43,45,49,52,53,} \\
55]\end{array}$ & $x$ & & $x$ & $x$ & $x$ \\
\hline & $\begin{array}{l}\text { Design quality and } \\
\text { packaging }\end{array}$ & & {$[18,36,43,58]$} & $x$ & & $x$ & & $x$ \\
\hline & Cost & & $\begin{array}{l}{[15-20,22-25,27,28,30-33,36-39,41,43} \\
47,49,51-54,57]\end{array}$ & $x$ & $x$ & $x$ & $x$ & $x$ \\
\hline \multirow[t]{4}{*}{ Outer setting } & $\begin{array}{l}\text { Patient needs and } \\
\text { resources }\end{array}$ & & {$[31,33,38,41,51]$} & $x$ & $x$ & $x$ & & \\
\hline & Cosmopolitanism & & {$[22,51]$} & & $x$ & & & \\
\hline & Peer pressure & & No data & & & & & \\
\hline & $\begin{array}{l}\text { External policy and } \\
\text { incentives }\end{array}$ & & $\begin{array}{l}{[16-20,24,28,30,31,33,36,37,39,48,49,} \\
51]\end{array}$ & $x$ & $x$ & $x$ & & $x$ \\
\hline \multirow[t]{14}{*}{ Inner setting } & Structural characteristics & & {$[18,27,37,44,49,52,57,58]$} & $x$ & $x$ & & & $x$ \\
\hline & $\begin{array}{l}\text { Networks and } \\
\text { communications }\end{array}$ & & {$[21,22,33,37,39,49,50,58]$} & $x$ & $x$ & & & $x$ \\
\hline & Culture & & {$[22,23,34,36,46,49,54]$} & $x$ & $x$ & $x$ & & $x$ \\
\hline & Implementation climate & & & & & & & \\
\hline & & Tension for change & No data & & & & & \\
\hline & & Compatibility & $\begin{array}{l}{[15-18,20,21,23,25,27,28,31,33,36,37,} \\
40,41,43,46-50,52,55-59,61]\end{array}$ & $x$ & $x$ & $x$ & & $x$ \\
\hline & & Relative priority & No data & & & & & \\
\hline & & $\begin{array}{l}\text { Organisational incentives and } \\
\text { rewards }\end{array}$ & {$[17,18,37,43]$} & $x$ & $x$ & $x$ & & $x$ \\
\hline & & Goals and feedback & {$[29,37,48,50,54,58]$} & $x$ & & $x$ & & $x$ \\
\hline & & Learning climate & No data & & & & & \\
\hline & & Readiness for implementation & {$[27,31-33,44,54,58]$} & $x$ & $x$ & & & $x$ \\
\hline & & Leadership engagement & {$[18,24,25,37,43,50,53,54,56,58]$} & $x$ & & $x$ & & $x$ \\
\hline & & Available resources & $\begin{array}{l}{[17,18,25,28,31,34,37,39,41,45,49-51} \\
53]\end{array}$ & $x$ & $x$ & $x$ & & $x$ \\
\hline & & $\begin{array}{l}\text { Access to knowledge and } \\
\text { information }\end{array}$ & $\begin{array}{l}{[15,16,18,20,21,23,25,28,31,37,39,41} \\
43,45,49-58]\end{array}$ & $x$ & $x$ & $x$ & & $x$ \\
\hline \multirow[t]{5}{*}{$\begin{array}{l}\text { Characteristics of } \\
\text { individuals }\end{array}$} & $\begin{array}{l}\text { Knowledge and beliefs } \\
\text { about the intervention }\end{array}$ & & $\begin{array}{l}{[16,18,20-25,27,28,30-34,37-39,41,} \\
43-47,49,51-54,56,57]\end{array}$ & $x$ & $x$ & $x$ & $x$ & $x$ \\
\hline & Self-efficacy & & {$[27]$} & $x$ & & & & \\
\hline & Individual stage of change & & {$[31-33,44]$} & & $x$ & & & \\
\hline & $\begin{array}{l}\text { Individual identification } \\
\text { with organisation }\end{array}$ & & {$[54,57]$} & $x$ & & & & $x$ \\
\hline & Other personal attributes & & $\begin{array}{l}{[16,18,23,25,28,34,36,37,41,43,46,52,} \\
56,57]\end{array}$ & $x$ & & $x$ & & $x$ \\
\hline \multirow[t]{2}{*}{ Process } & Planning & & {$[16,18,24,27,31-33,39-41,43,44,49-51]$} & $x$ & $x$ & $x$ & & $x$ \\
\hline & Engaging & & {$[21,31,37,50,54]$} & $x$ & $x$ & & & $x$ \\
\hline
\end{tabular}


Table 2 Summary of findings of factors important for the implementation of e-health (Continued)

\begin{tabular}{|c|c|c|c|c|c|c|}
\hline & Opinion leaders & {$[21,25,34,37,41,58]$} & $x$ & & $x$ & $x$ \\
\hline & $\begin{array}{l}\text { Formally appointed internal } \\
\text { implementation leaders }\end{array}$ & {$[18,27,32,39,44]$} & $x$ & $x$ & & \\
\hline & Champions & {$[18,20,25,29,31,32,36,37,39,51,54,58]$} & $x$ & $x$ & & $x$ \\
\hline & External change agents & No data & & & & \\
\hline & $\begin{array}{l}\text { Key stakeholders (Healthcare } \\
\text { professional) }\end{array}$ & {$[16,20,28,29,34,41,44,49-51,53-56,58]$} & $x$ & $x$ & $x$ & $x$ \\
\hline & $\begin{array}{l}\text { Innovation participants } \\
\text { (patients) }\end{array}$ & [20] & & $x$ & & \\
\hline Executing & & No data & & & & \\
\hline Reflecting and evaluating & & {$[16,24,29,31,34,41,43,48,50,51,53]$} & $x$ & $x$ & $x$ & $x$ \\
\hline
\end{tabular}

MS management systems, CS communication systems, CD clinical decision support systems, IS information systems, $R$ range systems from different e-health domains

were, for the most part, consistent with the constructs of the CFIR. Therefore, these detailed data were extracted from the studies into codes guided by the constructs of the CFIR (see Table 2). A category for data that did not fit into one of these constructs or for data that warranted further discussion between reviewers was created. This ensured that data were not being forced into the constructs where there was not a good fit and allowed for the CFIR to be evaluated as to how well the constructs could account for the data from this review. Cells within the matrix remained empty in cases where there were no relevant data in the paper concerned. As a way of remaining faithful to the meanings and concepts of each study, the terminology used in the original paper was preserved within the matrix. A category was also created for the main explanations or theories arising from the authors interpretations that were relevant to the research question. Data were recategorised from one construct to another and discussions between JR, EM and FS were held until the reviewers were confident that all data were coded into appropriate constructs or categories.

\section{Synthesising translations}

By reading the concepts and interpretations off the matrix, it was possible to establish a sense of the relationships between the studies. It became clear that the relationships between studies seemed to be reciprocal (where concepts of one study encompass another), with many themes occurring across studies which were largely in agreement about the factors that influenced implementation, and from which a line of argument (overarching narrative) could be developed. Following a process of meta-ethnography, meant themes from each of the studies were not just described and compared, but rather interrogated in relation to themes from other studies.

\section{Expressing the synthesis}

There were no data that could not be coded to one of the CFIR constructs, meaning the categories of the CFIR were endorsed and no additional original theoretical insights developed.

\section{Results}

\section{Search results}

A total of 2812 unique citations were identified (see Fig. 1). Of these, 2694 could be excluded on the basis of the title or abstract, leaving 118 citations requiring the full paper before a decision could be made. Of the 118 full papers assessed, 44 [15-58] met the criteria for inclusion and were included in this review (Additional file 2 gives details of all included reviews).

\section{Description of the included reviews}

All studies were published between 2003 and 2014. Fifteen studies originated from Canada [16, 25-29, 31-33, $36,39,41,42,44,53]$, fourteen from the USA [17, 22$24,30,35,38,40,49,52,54-57]$, three from the Netherlands [17, 20, 34], three from the UK [37, 46, 51], two from Australia $[15,43]$ and one each from Germany [47], Sweden [50], Norway [19], Mexico [21], Malaysia [58], Kenya [45] and Israel [48]. All papers were written in English.

Of the 44 studies, 28 focussed specifically on one domain of e-health including: management systems [24, 29] such as electronic medical records $[16,18,21,28$, $36,39,41,54,55]$ or e-prescribing [27]; communication systems such as telemedicine $[20,22,31,44,51]$, telehealth [17, 32, 33] and home telecare systems [19]; and computerised decision support systems [34, 40, 42, 43, $45,48]$ and information systems [38]. Sixteen studies focussed on e-health technologies from across a range of e-health domains $[15,23,25,26,30,35,37,46,47,49$, $50,52,53,56-58]$. 
Twelve studies were focussed on one particular type of healthcare setting including primary care/ambulatory $[15,24,27,28,36,39]$, hospital/inpatient/acute care [22, $29,40,46]$ and home care $[19,53]$. Twenty-one studies focussed on the implementation of e-health in to two or more types of healthcare setting $[21,23,25,26,30,31$, $33,35,37,41-45,47,49,50,52,54-56]$; the remainder of the studies did not define a specific healthcare setting $[16,18,20,28,34,38,48,57,58]$.

When judged against the ENTREQ statement [11], many studies were methodologically poor. For example, three $[30,33,58]$ did not give details of databases searched and seven searched only one database or source, such as the proceedings of a particular conference [19, 20, 27, 38, 44, 48, 54]. Information about study selection criteria was also inadequate: Sixteen of the 44 studies did not specify the criteria for inclusion or exclusion $[16,17,20,22,30,32-36,38-40,48,53,56]$. Five did not detail the number of primary studies included in the review [22, 32, 40, 44, 48].

\section{Factors that influence implementation}

The synthesised data from the included studies is presented, classified by the main constructs of the CFIR. There were no data that could not be coded to one of the CFIR constructs. A description of the constructs for which there were most supporting data is described below. A summary of the findings is presented in Table 2 which includes details of the constructs for which there were little or no supporting data and thus not described in the main text. Recommendations for implementation of e-health based on these findings are presented in Table 3.

\section{Innovation characteristics Adaptability}

An important factor in vendor and technology selection, reported by many studies from all e-health domains, was the ability of the technology to be adapted to fit the local context [34, 39]. Technologies that can have technical adjustments made to them to suit the constant modifications of the environment may have greater acceptance and adoption [18, 35, 41, 50, 58]. End user input in the design and development of e-health technologies should be considered as a way of overcoming barriers of adaptability [28].

Related to adaptability is the interoperability of systems reported by many studies $[16,18,21,22,24,25,28$, $38,48-50,52,53]$. To promote their acceptance and use, systems must be able to adequately interface with other IT systems and exchange information [18, 27, 49]. For example, a major barrier to the adoption of Electronic Health Records (EHR) was the inability of new
Table 3 Recommendations for implementation based on data from reviews

- Selection of an appropriate e-health system needs careful consider-
ation taking into account:
o Complexity
o Adaptability
o Compatibility with existing systems and work practices
o Cost
- Key stakeholders and implementation champions should be included
as early as possible in the implementation process.
- Sufficient financial and legislative support needs to be in place to
support implementation.
- Standards for technology which address inter-operability, security and
privacy may improve acceptability and implementation.
- Planning implementation is a critical step which includes ensuring that
organisations are in a state of readiness.
- The provision of training and education to all those involved with
implementation is a key success factor.
- Implementation does not stop with 'go-live'-there is a need for
ongoing monitoring, evaluation and adaptation of systems to ensure
intended goals are being met, benefits realised, and ongoing
identification of barriers to effective use, along with strategies to
overcome these barriers.

systems to exchange information with systems already in place, due to a lack of consistent data standards [18].

\section{Complexity}

Complexity factors such as slow system performance [55], software and hardware that were difficult to use [27], the need for extensive software modifications [52], the work involved in transferring records between two systems [18], the inability to provide real-time access [38], data handling, reliability, slow speed, unplanned downtime [41] and connectivity issues [49] influence implementation of systems in healthcare settings. Often issues of complexity were linked to health professionals being unable to master the technologies that were implemented [18, 28]. Vendors of e-health systems should aim to make systems as user-friendly as possible, involving end users in the design and development [53], providing guides to their use [34] and providing technical assistance [43].

\section{Cost}

The cost of e-health system and costs associated with their implementation were reported as important implementation factors by the majority of studies across all ehealth domains $[15-19,22-25,27,28,30-33,36,38,39$, $41,43,47,49,51-54,57]$, with some studies citing costrelated factors as the main barrier to implementation $[49,54]$. Cost factors are related to start-up costs, ongoing costs, costs related to a loss of revenue and potential savings to put against these costs. 
High set-up costs including purchasing and installation costs were cited as barriers to the initial adoption of e-health systems [49]. Financial incentives to adopt ehealth systems from insurers and government agencies facilitated adoption decisions in some case [24, 37, 49].

Concerns about ongoing costs were also reported as barriers to adoption [17, 49]. Evidence of cost-saving and returns on investment were shown to be important in ongoing use of technologies [36, 39]. Establishing cost-effectiveness through formal evaluations, financing of services on a bigger scale, and redesigning business models and incentives were suggested as strategies to help overcome cost-related barriers [20, 24, 51].

\section{Outer setting}

\section{External policy and incentives}

An absence or inadequacy of legislation and policies and liability concerns may hamper the implementation of ehealth systems at the organisational and health professional level $[17,18,20,51]$. The need for recognised standards for the provision of e-health systems was described by many studies $[16,18,20,28,33,36,48,49,51]$. The creation of standards may serve to reduce health professionals' concerns over patient data safety and professional liability $[17,33]$ and facilitate the exchange of electronic health information between systems [16] and organisations while maintaining data integrity [49].

Incentives by government organisations and other external stakeholders may facilitate adoption by healthcare organisations [17, 18, 39, 48, 49]. Financial incentives include the provision of initial funds to cover upfront costs [49], financial sponsorship [39], reimbursements for adoption [19, 30, 31, 36], and pay-for-performance initiatives $[24,36,37,49]$.

\section{Inner setting}

\section{Implementation climate}

Implementation climate includes the compatibility or general fit between the e-health intervention and the organisation [16, 23, 31, 33, 37, 46, 49, 59]. The fit between e-health systems and workflows in particular was discussed by the majority of studies $[15,16,18,21,23,25$, $27,28,36,40,41,43,47-50,52,55-58]$. A frequent reason for unsuccessful implementation is that the information systems do not fit well with work practices or daily clinical work [25]. Health professionals' perceptions that e-health systems disrupt workflows, and the delivery of care, are a barrier to both the implementation and use of these systems $[23,49,52,56,57]$. When there is a good fit, or perceived fit, between e-health systems and workflows, and when systems positively influence workplace efficiency, this facilitates use [15, 40, 41]. Incorporating workflow analysis into system design $[48,55]$, the integration of systems into the usual process of care
[15], user-friendly systems [40] and minimising workflow interruptions during implementation [17] may minimise disruptions to workflow.

Alterations to workflows created by the introduction of e-health systems may also disrupt established professional roles, responsibilities $[16,20,25,36,55]$ and working styles [18]. Physician resistance to e-health implementation is reported by several studies to be related to fear of [18], dissatisfaction with [18] and uncertainty over $[43,47]$ new roles and responsibilities, created by the introduction of e-health systems [18]. The quality of project management during the implementation period [18], careful study of the downstream effects of implementation on workflow [55], additional training [31, 55], the adaptability of technologies to fit with roles, tasks and workflows [37] and dedicated technical support staff [31] are suggested as strategies to reduce barriers related to disruptions to workflow, roles and responsibilities that e-health implementation may bring.

Leadership engagement at all stages of the development and implementation processes can help improve the effective implementation of e-health systems [43, 54, $56,58]$ and a lack of involvement can be a barrier to implementation $[18,53]$. Management support is also important for implementation success [25, 37, 50, 54].

Authors described available resources including the availability of suitable infrastructure as important for implementation success. Infrastructure features included electricity supply [51], available bandwidth [31, 51], access to reliable internet connectivity $[45,51]$, access to computers [34], electrical power [45] and access to phone lines and mobile phones [45]. The availability, or lack thereof, of time to learn new e-health systems, implement them [25, 37, 53] and train staff to use them [49] was reported by several studies as a resource factor important for implementation. Providing a period of transition in which end users can become familiar with and learn how to use new systems has been advocated $[39,50]$.

Access to knowledge and information was also important for the implementation of systems across all e-health domains. Education was reported to increase staff acceptance of e-health systems [16, 25, 41, 45] including education around anticipated benefits and when those benefits could be expected [54]. A lack of knowledge and a limited understanding of benefits afforded by the systems acted as a barrier to implementation [49, 52, 53]. Nearly all studies made reference to training and support in relation to implementation and acceptance of e-health systems. Generally, access to appropriate, highquality, well-funded, and easily available training was reported as a facilitator to implementation, whereas it was reported as a barrier when it was non-existent or existent but inadequate $[15,16,18,20,23,25,28,31,37,43$, 
$45,50,51,53-58]$. Access to ongoing support to use systems was important for system use [21, 25, 28, 31, 37, $39,43,54]$ and a barrier to implementation when it was lacking [21].

\section{Individual characteristics \\ Knowledge and beliefs}

Attitudes and beliefs were reported to act as both facilitators and barriers to implementation and acceptance of e-health systems across all e-health domains. Positive attitudes of practitioners toward e-health systems and their implementation increased acceptance and implementation [20, 21, 41, 44, 46, 49], whereas negative attitudes and staff resistance acted as barriers [49, 52]. Positive staff attitudes were described as: beliefs that the new systems would benefit patients [56], interest in the technologies, perceived usefulness and motivation in working with the systems [21]. Negative perceptions included beliefs that electronic systems would disrupt the delivery of care [49]; doubts that these systems can improve patient care, clinical outcomes or improve the quality of medical practices [43]; and distrust in the systems [37] as well as a more general staff resistance to change [28, 32, 39, 41, 49, 51-53]. Strategies to challenge negative attitudes included fostering a culture of communication and cooperation, involving the eventual users of systems in the development and implementation [20, 49], leadership [56], friendly and context-aware user interfaces which promote perceived ease of use and usefulness [21], better education [47], and clearly and prospectively communicating intended benefits and realistic expectations for the system [54]. The attitudes of colleagues $[25,41]$ and patients $[25,27,41]$ were also reported to influence staff attitudes with regard to e-health acceptance as were staff demographic factors [23, 46, 56].

Specifically, fears over a loss of autonomy [16, 18, 27, $34,37,39,43]$, concerns about liability [16, 18, 22, 37, $43,51]$, concerns over patient privacy and security being compromised $[16,18,20,23,24,27,28,30,31,33,39$, $41,43,45,47,49,51-53,56,57]$, and perceived threats to patient and health professional relationships $[18,25$, $27,28,31,34,37-39,41,43,54,57]$ through the introduction of e-health systems were repeatedly reported as barriers to use.

\section{Other personal attributes}

Healthcare professionals' computer skills, abilities and experience were cited by several studies as influencing implementation and acceptance of e-health systems [16, $18,25,28,34,36,37,41,43,52$, 57]. Training [25, 37, 43] and financial incentives [37] were cited as strategies to overcome skill-related barriers. Demographic factors such as age, education, sex, nationality, and clinical experience may influence healthcare professionals' attitudes towards e-health systems [23, 28, 46, 56, 57]; however, most studies conclude that no clear relationships between these characteristics and attitudes could be established [46, 56, 57].

\section{Process \\ Planning}

Planning for implementation was important for success, whereas the lack of a strategic plan was reported as a barrier to e-health implementation [24, 27, 31, 44, 50]. The work of planning includes the delineation of roles and responsibilities [43], securing time to invest system selection and procurement [18], evaluating other concomitant policy and process changes [40], needs assessment and analysis, development of a business plan [44], early identification and engagement of champions [31], involving end users [16, 27, 41, 51], establishing a guiding philosophy [33], testing organisational readiness [27, 32 ], development of incentive and innovation structures [27], communication of the strategy to all staff [50], and development of protocols for using the system and for provision of training [31]. Incremental implementation strategies where features are made available to users according to a plan were cited as preferable to 'big bang' approaches to implementation within complex organisations $[39,49]$. One review emphasised the need for ongoing effort after the initial 'go-live' phase, referring to the 'under-recognised maintenance phase of implementation' [29].

\section{Engaging}

The designation of champions [18, 20, 25, 29, 31, 32, 36, $37,39,51,54,58]$ may be important for implementation success. Engagement of key stakeholders in the development and selection of e-health systems and in the planning and execution of implementation processes were important for implementation [16, 20, 28, 29, 34, 41, 44, 49-51, 53-56, 58] through fostering a sense of ownership [20, 44, 51], confidence [28], acceptance [34], enjoyment and self-pride [20] towards the e-health system and increasing buy-in [54].

\section{Reflecting and evaluating}

Evaluation was seen as important to ensure system benefits $[29,48]$, to increase health professional acceptance through demonstration of benefits [31, 34, 41, 43] and to secure ongoing funding [53], whereas a lack of evaluation and evidence may act as a barrier to implementation [53]. Four reviews included data on the effects of the e-health systems implemented [24, 36, 49, 52]; these reported mixed effects. 


\section{Recommendations}

A summary of recommendations for implementation of an e-health system is presented in Table 3.

\section{Discussion}

This review identified and synthesised a large body of literature on the implementation of e-health which covered a wide range of healthcare systems and e-health. Findings suggest that issues around implementation are multi-level and complex. All the included reviews reported multiple factors that were important for implementation, and no single factor was identified as a key barrier or facilitator. The synthesis showed that findings were remarkably consistent across different e-health domains and healthcare settings and well described by the CFIR framework, with no data that did not fit the CFIR.

Key factors for effective implementation included outer context, in particular, the need for supportive legislation, and recognised standards. The fit of e-health systems with current organisational workflow was another key factor.

In comparing the findings of this review with the one it updates [7], it appears that many implementation factors are consistent over time, such as the prevailing focus on organisational issues including the need for adequate resources, particularly financial, policy support, standards and interoperability. This suggests that although e-health may be a rapidly changing field, many of the challenges of implementing systems within organisations remain constant over time. However, some notable differences exist between the findings of the two reviews. The original review reported a concentration on organisational issues within the literature. Although also strongly present in this review, the use of the CFIR sensitised the focus of analysis to other factors as well including factors related to the innovation, outer context, individuals and the process of implementation. The original authors reported that very little attention had been paid in ensuring that the potential benefits of new technologies are made transparent through ongoing evaluation and feedback. In this review, there was a focus given to the role of reflecting and evaluating which may represent an increased awareness of their importance in implementation.

The results from this review are comparable to another large systematic review of reviews by Lau et al. which synthesised the literature on the barriers and facilitators to the implementation of complex innovations within primary care settings [60]. Both reviews highlighted the importance of policies and incentives; adequate infrastructure and resources; engagement of key personnel; organisational readiness; individuals' knowledge and beliefs; and the fit of innovations with workflows, processes and systems. As such, it seems these factors are important for implementation across interventions and healthcare settings. Lau et al.'s review found that the perceived benefits or harm of implementation such as expectations of more efficient workflow or lower productivity were only an important factor for the implementation of e-health interventions and was not present in the data for other types of interventions (guidelines or evidence-based practice, management of care, public health or preventative medicine, integration of new role or collaborative working). Adaptability and cost were only present in the data for e-health interventions and one other type of intervention. These factors were given a lot of focus in the current review thus suggesting that these factors may be unique or particularly relevant to e-health implementation.

\section{Methodological strengths and weaknesses}

Conducting a systematic review of reviews, given the enormous literature reporting on the implementation of e-health, provided a useful and economical way to manage evidence across a broad topic area. This review allowed the findings of many separate reviews to be compared and contrasted and provided a summary of evidence from reviews which focussed on different ehealth interventions and different healthcare settings. The use of a meta-ethnographic approach provided a rigorous and transparent approach to the data analysis and the translation of the studies into one another, which allowed the development of an overarching narrative which endorsed the value of the CFIR framework.

Although this review was rigorous, carefully executed and employed a robust methodological approach, it has several limitations. Systematic reviews, and also the studies included in them, may be subject to publication bias. Reviews of reviews inevitably result in a time-lag, as new primary data must first be published, then included in a review and then into a review of reviews. Other limitations include the fact that this review was dependent on the interpretations of primary data provided by the authors of included reviews. It was often not clear whether the data came from the primary studies or were subsequent interpretations by the authors of included reviews. Many reviews did not specify whether the data came from clinicians, nurses, other primary care staff or multidisciplinary teams; therefore, it was not possible to differentiate the perspectives of specific roles (e.g. nurses). We recommend that authors of implementation studies adhere to reporting guidelines, such as the forthcoming Standards for Reporting Implementation Studies (StaRI) (Pinnock et al., submitted for publication). Finally, the data available for the synthesis was limited by what previous reviewers included in their reviews, and therefore, it is not possible to tell whether the 
areas of the CFIR which are not addressed are not important or just not addressed.

\section{Conclusions}

We took a multi-level approach to synthesise data from 44 reviews, addressing factors important for the implementation of e-health across healthcare settings. The use of the CFIR highlighted that the individual e-health technology, the outer setting, the inner setting, the individual health professionals, and the process of implementation are all important for implementation and should be considered carefully when attempts are made to implement e-health into health systems. Particular consideration should be paid to the fit of e-health with external and internal contexts. The use of the CFIR allowed the identification of areas that received little attention in the literature which may represent potential themes for future research including the source and trialability of ehealth systems, the relative priority given to the systems, the role of external change agents and the involvement of innovation participants (patients).

\section{Additional files}

Additional file 1: MEDLINE search strategy. (DOCX $15 \mathrm{~kb}$ )

Additional file 2: Summary details of the 44 included studies. (DOCX $30 \mathrm{~kb}$ )

\section{Abbreviations}

CFIR: Consolidated Framework for Integrating Research; ENTREQ: Enhancing transparency in reporting the synthesis of qualitative research; NHS: National Health Service; PRISMA: Preferred Reporting Items for Systematic Reviews and Meta-Analyses

\section{Acknowledgements}

We are grateful to the authors of the original systematic review (Professor Frances Mair, Professor Carl May, Professor Elizabeth Murray, Dr. Tracy Finch, Dr George Anderson, Professor Catherine O'Donnell, Professor Paul Wallace and Professor Frank Sullivan) for allowing us to update their work. We are grateful to the reviewers for their insightful comments.

\section{Funding}

This publication presents an independent research funded by the National Institute for Health Research (NIHR) under its Programme Grants for Applied Research Programme (Grant Reference Number RP-PG-0609-10135). The views expressed are those of the author(s) and not necessarily those of the NHS, the NIHR or the Department of Health. This literature review was undertaken as part of the lead author's self-funded PhD conducted while employed on the above programme grant, and this research contributes to the overall grant.

\section{Availability of data and material}

Not applicable

\section{Authors' contributions}

JR developed and refined the study protocol (based on the origina systematic review of reviews [7]) with contributions from all co-authors (FS, $\mathrm{EM}$ and $\mathrm{RL}$ ). JR prepared the manuscript. JR undertook the data collection (literature search, data extraction), analysis, interpretation and report writing. $\mathrm{RL}$ double screened all citations, abstracts and full papers. EM checked the data extraction and coding. EM and FS contributed to the coding, data interpretation and synthesis and provided methodological guidance. All authors read and approved the final manuscript.

\section{Competing interests}

Professor Elizabeth Murray was a co-author on the original systematic review of reviews that was updated [7]. All other authors declare that they have no competing interests.

\section{Consent for publication}

Not applicable

Ethics approval and consent to participate

Not applicable

Received: 23 June 2016 Accepted: 13 October 2016

Published online: 26 October 2016

\section{References}

1. Currie WL, Seddon JJ. A cross-national analysis of eHealth in the European Union: some policy and research directions. Inf Manage. 2014;51(6):783-97.

2. Lewis T, Synowiec C, Lagomarsino G, Schweitzer J. E-health in low- and middle-income countries: findings from the Center for Health Market Innovations. Bull World Health Organ. 2012;90(5):332-40.

3. van Gemert-Pijnen J, Wynchank S, Covvey H, Ossebaard H. Improving the credibility of electronic health technologies. Bull World Health Organ. 2012; 90(5):323-A.

4. Wachter RM. Making IT Work: Harnessing the power of health information technology to improve care in England. Report of the National Advisory Group on Health Information Technology in England. 2016. https://www. gov.uk/government/uploads/system/uploads/attachment_data/file/550866/ Wachter_Review_Accessible.pdf. Accessed 27 Sept 2016.

5. NHS England. Five Year Forward View. 2014. https://www.england.nhs.uk/ wp-content/uploads/2014/10/5yfv-web.pdf. Accessed 17 Jun 2016.

6. Computing. Addenbrooke's Hospital $£ 200 \mathrm{~m}$ IT system proves an epic fail. 2015. http://www.computing.co.uk/ctg/news/2427100/addenbrookes-hospitalgbp200m-it-system-proves-an-epic-fail. Accessed 17 Jun 2016.

7. Mair FS, May C, O'Donnell C, Finch T, Sullivan F, Murray E. Factors that promote or inhibit the implementation of e-health systems: an explanatory systematic review. Bull World Health Organ. 2012;90(5):357-64.

8. Damschroder LJ, Aron DC, Keith RE, Kirsh SR, Alexander JA, Lowery JC. Fostering implementation of health services research findings into practice: a consolidated framework for advancing implementation science. Implement Sci. 2009;4:50.

9. Ross J, Stevenson F, Lau R, Murray E. Exploring the challenges of implementing e-health: a protocol for an update of a systematic review of reviews. BMJ Open. 2015;5(4):e006773.

10. Smith V, Devane D, Begley C, Clarke M. Methodology in conducting a systematic review of systematic reviews of healthcare interventions. BMC Med Res Methodol. 2011;11(1):15

11. Tong A, Flemming K, Mclnnes E, Oliver S, Craig J. Enhancing transparency in reporting the synthesis of qualitative research: ENTREQ. BMC Med Res Methodol. 2012;12:181

12. Liberati A, Altman DG, Tetzlaff J, Mulrow C, Gotzsche PC, loannidis JP, et al. The PRISMA statement for reporting systematic reviews and meta-analyses of studies that evaluate healthcare interventions: explanation and elaboration. BMJ (Clinical Research Ed). 2009;339:b2700.

13. Noblit GW, Hare RD. Meta-ethnography: synthesizing qualitative studies. Newbury Park: Sage;1988.

14. Bearman M, Dawson P. Qualitative synthesis and systematic review in health professions education. Med Educ. 2013;47(3):252-60

15. Adaji A, Schattner $P$, Jones $K$. The use of information technology to enhance diabetes management in primary care: a literature review. Inform Prim Care. 2008;16(3):229-37.

16. Archer N, Fevrier-Thomas U, Lokker C, McKibbon KA, Straus SE. Personal health records: a scoping review. J Am Med Inform Assoc. 2011;18(4):515-22.

17. Benavides-Vaello S, Strode A, Sheeran BC. Using technology in the delivery of mental health and substance abuse treatment in rural communities: a review. J Behav Health Serv Res. 2013;40(1):111-20.

18. Boonstra A, Broekhuis M. Barriers to the acceptance of electronic medical records by physicians from systematic review to taxonomy and interventions. BMC Health Serv Res. 2010;10:231.

19. Botsis T, Hartvigsen G. Current status and future perspectives in telecare for elderly people suffering from chronic diseases. J Telemed Telecare. 2008; 14(4):195-203. 
20. Broens TH, Huis in't Veld RM, Vollenbroek-Hutten MM, Hermens HJ, van Halteren AT, Nieuwenhuis LJ. Determinants of successful telemedicine implementations: a literature study. J Telemed Telecare. 2007;13(6):303-9.

21. Castillo VH, Martinez-Garcia Al, Pulido JR. A knowledge-based taxonomy of critical factors for adopting electronic health record systems by physicians: a systematic literature review. BMC Med Inform Decis Mak. 2010;10:60.

22. Demaerschalk BM, Miley ML, Kiernan T-EJ, et al. Stroke Telemedicine. Mayo Clinic Proceedings. 2009;84(1):53-64.

23. Fitzpatrick L, Melnikas A, Weathers M, Kachnowski S. Understanding communication capacity. Communication patterns and ICT usage in clinical settings. J Healthc Inf Manag. 2007;22(3):34-41.

24. Fontaine $P$, Ross SE, Zink T, Schilling LM. Systematic review of health information exchange in primary care practices. J Am Board Fam Med. 2010;23(5):655-70.

25. Gagnon MP, Desmartis M, Labrecque M, Car J, Pagliari C, Pluye P, et al. Systematic review of factors influencing the adoption of information and communication technologies by healthcare professionals. J Med Syst. 2012; 36(1):241-77.

26. Gagnon MP, Legare F, Labrecque M, Fremont P, Pluye P, Gagnon J, Car J, et al. Interventions for promoting information and communication technologies adoption in healthcare professionals (review). Cochrane Database Syst Rev. 2009;1:CD006093.

27. Gagnon M-P, Nsangou E-R, Payne-Gagnon J, Grenier S, Sicotte C. Barriers and facilitators to implementing electronic prescription: a systematic review of user groups' perceptions. J Am Med Inform Assoc. 2014;21(3):535-41.

28. Goldstein DH, Phelan R, Wilson R, Ross-White A, VanDenKerkhof EG, Penning JP, et al. Brief review: adoption of electronic medical records to enhance acute pain management. Can J Anesth. 2014;61(2):164-79.

29. Gruber D, Cummings GG, Leblanc L, Smith DL. Factors influencing outcomes of clinical information systems implementation: a systematic review. Comput Inform Nurs. 2009;27(3):151-63.

30. Hsieh CT, Lin B. Information technology for competitive advantage: the case of learning and innovation in behavioural healthcare service. Int J Electron Healthc. 2011;6(2-4):213-28.

31. Jarvis-Selinger S, Chan E, Payne R, Plohman K, Ho K. Clinical telehealth across the disciplines: lessons learned. Telemed e-Health. 2008;14(7):720-5.

32. Jennett PA, Gagnon MP, Brandstadt HK. Preparing for success: readiness models for rural telehealth. J Postgrad Med. 2005;51(4):279.

33. Jennett PA, Scott RE, Affleck Hall L, Hailey D, Ohinmaa A, Anderson C, Thomas $\mathrm{R}$, Young $\mathrm{B}$, Lorenzetti $\mathrm{D}$. Policy implications associated with the socioeconomic and health system impact of telehealth: a case study from Canada. Telemed J E Health. 2004;10(1):77-83.

34. Kilsdonk E, Peute LW, Knijnenburg SL, Jaspers MW. Factors known to influence acceptance of clinical decision support systems. Stud Health Technol Inform. 2011;169:150-4.

35. Kukafka R, Johnson SB, Linfante A, Allegrante JP. Grounding a new information technology implementation framework in behavioral science: a systematic analysis of the literature on IT use. J Biomed Inform. 2003;36(3):218-27.

36. Lau F, Price M, Boyd J, Partridge C, Bell H, Raworth R. Impact of electronic medical record on physician practice in office settings: a systematic review. BMC Med Inform Decis Mak. 2012;12:10.

37. Lluch M. Healthcare professionals' organisational barriers to health information technologies-a literature review. Int J Med Inform. 2011;80(12):849-62.

38. Lu YC, Xiao Y, Sears A, Jacko JA. A review and a framework of handheld computer adoption in healthcare. Int J Med Inform. 2005;74(5):409-22.

39. Ludwick DA, Doucette J. Adopting electronic medical records in primary care: lessons learned from health information systems implementation experience in seven countries. Int J Med Inform. 2009;78(1):22-31.

40. Mack EH, Wheeler DS, Embi PJ. Clinical decision support systems in the pediatric intensive care unit. Pediatric Crit Care Med. 2009;10(1):23-8.

41. McGinn CA, Grenier S, Duplantie J, Shaw N, Sicotte C, Mathieu L, et al. Comparison of user groups' perspectives of barriers and facilitators to implementing electronic health records: a systematic review. BMC Med. 2011;9:46.

42. Mollon B, Chong JJ, Holbrook AM, Sung M, Thabane L, Foster G. Features predicting the success of computerized decision support for prescribing: a systematic review of randomized controlled trials. BMC Med Inform Decis Mak. 2009;9(1):11.

43. Moxey A, Robertson J, Newby D, Hains I, Williamson M, Pearson SA. Computerized clinical decision support for prescribing: provision does not guarantee uptake. J Am Med Inform Assoc. 2010;17(1):25-33.
44. Ohinmaa A. What lessons can be learned from telemedicine programmes in other countries? J Telemed Telecare. 2006;12 suppl 2:40-4.

45. Oluoch T, Santas X, Kwaro D, Were M, Biondich P, Bailey C, et al. The effect of electronic medical record-based clinical decision support on HIV care in resource-constrained settings: a systematic review. Int J Med Inform. 2012; 81(10):e83-92

46. Oroviogoicoechea C, Elliott B, Watson R. Review: evaluating information systems in nursing. J Clin Nurs. 2008;17(5):567-75.

47. Orwat C, Graefe A, Faulwasser T. Towards pervasive computing in health care-a literature review. BMC Med Inform Decis Mak. 2008;8(1):26.

48. Peleg M, Tu S. Decision support, knowledge representation and management in medicine. Yearbook Med Inform. 2006:72-80.

49. Police RL, Foster T, Wong KS. Adoption and use of health information technology in physician practice organisations: systematic review. Inform Prim Care. 2010;18(4):245-58

50. Rahimi B, Vimarlund V, Timpka T. Health information system implementation: a qualitative meta-analysis. J Med Syst. 2009;33(5):359-68.

51. Saliba V, Legido-Quigley H, Hallik R, Aaviksoo A, Car J, McKee M. Telemedicine across borders: a systematic review of factors that hinder or support implementation. Int J Med Inform. 2012;81(12):793-809.

52. Shekelle P, Morton SC, Keeler EB. Costs and Benefits of Health Information Technology. Rockville (MD): Agency for Healthcare Research and Quality (US); 2006 Apr. (Evidence Reports/Technology Assessments, No. 132. ) Available from: https://www.ncbi.nlm.nih.gov/books/NBK37988/.

53. Stolee P, Steeves B, Glenny C, Filsinger S. The use of electronic health information systems in home care: facilitators and barriers. Home Healthc Nurse. 2010;28(3):167-79.

54. Studer M. The effect of organizational factors on the effectiveness of EMR system implementation-what have we learned? Healthc Q. 2005;8(4):92-8.

55. Vreeman DJ, Taggard SL, Rhine MD, Worrell TW. Evidence for electronic health record systems in physical therapy. Phys Ther. 2006;86(3):434-46.

56. Waneka R, Spetz J. Hospital information technology systems' impact on nurses and nursing care. J Nurs Adm. 2010;40(12):509-14.

57. Yarbrough AK, Smith TB. Technology acceptance among physicians: a new take on TAM. Medical Care Research and Review. 2007:64(6):650-72.

58. Yusof MM, Stergioulas L, Zugic J. Health information systems adoption: findings from a systematic review. Stud Health Technol Inform. 2007:129(1):262

59. Charnock D, Shepperd S. Learning to DISCERN online: applying an appraisal tool to health websites in a workshop setting. Health Educ Res. 2004;19(4):440-6.

60. Lau R, Stevenson F, Ong BN, Dziedzic K, Treweek S, Eldridge S, et al. Achieving change in primary care-causes of the evidence to practice gap: systematic reviews of reviews. Implement Sci. 2016;11(1):1-39.

61. Atkinson NL, Massett HA, Mylks C, McCormack LA, Kish-Doto J, Hesse BW, et al. Assessing the impact of user-centered research on a clinical trial eHealth tool via counterbalanced research design. J Am Med Inform Assoc. 2011;18(1):24-31.

\section{Submit your next manuscript to BioMed Central and we will help you at every step:}

- We accept pre-submission inquiries

- Our selector tool helps you to find the most relevant journal

- We provide round the clock customer support

- Convenient online submission

- Thorough peer review

- Inclusion in PubMed and all major indexing services

- Maximum visibility for your research

Submit your manuscript at www.biomedcentral.com/submit 